\title{
KUALITAS LULUSAN DAN ORIENTASI BIDANG PEKERJAAN TERHADAP KEMAMPUAN MENGHADAPI PERSAINGAN KERJA PADA MAHASISWA PERGURUAN TINGGI
}

\author{
Anita Ria ${ }^{1}$, Didi Zainuddin ${ }^{2}$ \\ Pendidikan Ekonomi, FIPPS, Universitas Indraprasta PGRI ${ }^{1}$ \\ Teknik Industri, FTIK, Universitas Indraprasta PGRI ${ }^{2}$ \\ anitarianita@gmail.com ${ }^{1}$, didiza.gadept@gmail.com ${ }^{2}$
}

\begin{abstract}
This study aims to determine the quality of graduates and the orientation of the work field to the ability to face job competition in students of private universities in South Jakarta and research using quantitative methods with correlation and multiple regression approaches, while the results of this study have a significant effect on graduate quality and orientation the field of work together towards the ability to face job competition. This is evidenced by the calculation $=14,243$ and sig. $0,000<0,05$ and the coefficient of determination $\mathrm{r} 2$ amounted to $0,608(60,8 \%)$ this shows that the ability of job competition is influenced by the quality of graduates and the orientation of the work field by $60.8 \%$.
\end{abstract}

Keyword : Quality of Graduates, Work Orientation, Job Competition Capability

\section{PENDAHULUAN}

Di era industri 4.0 pertumbuhan ekonomi dan teknologi semakin berkembang, idealnya jika ada suatu pertumbuhan dan perkembangan disuatu negara maka akan membutuhkan dan menyerap tenaga kerja yang banyak pula, akan tetapi tidak di pungkiri bahwa persaingan dalam mendapatkan lapangan pekerjaan pun tidak semudah yang dibayangkan. dimana lapangan pekerjaan yang ditawarkan tidak sebanding dengan jumlah peningkatan sarjana setiap tahunnya dari seluruh perguruan tinggi pencetak sarjana muda. Dimana pertumbuhan angkatan kerja pertahunnya mencapai 2 juta pencari kerja. Dan pengangguran yang paling banyak dari kalangan lulusan perguruan tinggi khususnya. Oleh karena itu, para calon sarjana dituntut untuk lebih inovatif, kreatif, memiliki keterampilan kerja dan kepribadian yang baik.

Hal ini juga disampaikan dengan data BPS yang diolah tim Lokadata Beritagar.id, bahwa jumlah angkatan kerja yang ada di Indonesia yang diumumkan pada bulan Agustus 2018 lalu sebanyak 131,01 juta orang, dalam hal ini naik sebesar 2,95 juta orang dibandingkan pada bulan Agustus 2017 lalu dalam kurun waktu satu tahun. Kemudian sejalan juga dengan hal itu, pada data Tingkat Partisipasi Angkatan Kerja (TPAK) ternyata juga meningkat 0,59 persen pada 
Research and Development Journal Of Education

Vol. 5 No. 2 April 2019

p-ISSN 2406-9744

e-ISSN 2657-1056

tahun yang sama. Adapun masalah ketenagakerjaan yang perlu diperhatikan dan dicarikan solusinya adalah kurangnya kompetensi dan daya saing tenaga kerja Indonesia khususnya lulusan dari perguruan tinggi.

Sehingga dalam menghadapi revolusi industri 4.0, tenaga kerja Indonesia dianggap belum memiliki kesiapan dan keterampilan (skill) yang mumpuni. Karena kekurangan skill turut disebabkan oleh rendahnya pelatihan keterampilan dan keahlian yang diterima tenaga kerja sebelum memasuki dunia kerja. kebutuhan pasar lapangan kerja yang tersedia sebenarnya yang menjadi kendala utama bagi seorang sarjana untuk mendapatkan pekerjaan adalah kesiapan mereka untuk bekerja, rendahnya kualitas sarjana dan tidak sesuainya bidang yang akan mereka tekuni dengan dunia kerja mereka.

Subjek dalam penelitian ini adalah para mahasiswa semester akhir yang merupakan calon lulusan yang nantinya akan memasuki ke dunia kerja, karena pada umumnya mahasiswa tingkat akhir harus mulai berfikir tentang masa depannya mengenai pekerjaan yang sesuai dibidang keahliannya setelah lulus dari Perguruan Tinggi. Alumni/lulusan sarjana diharapkan memiliki kemampuan sesuai dengan bidangnya, mampu mengembangkan pengetahuannya, memiliki wawasan dan pengetahuan yang luas tentang berbagai macam informasi. Penguasaan dalam teknologi komputer merupakan komponen penting dari sistem informasi dalam meningkatkan kemampuan diri. Karena tanpa adanya kemampuan diri dibidang teknologi, akan menjadi penghambat bagi alumni/lulusan sarjana untuk berkembang cepat mengikuti zaman, Oleh karena nya calon sarjana yang akan mencari pekerjaan harus memahami teknologi dan memiliki keterampilan kerja yang baik serta mampu mengikuti perkembangan zaman yang sedang dibutuhkan dalam lapangan kerja.

Lalu strategi yang harus diterapkan oleh calon sarjana dalam mencari kerja agar dapat diserap oleh lapangan pekerjaan yaitu menyesuaikan kemampuan yang dimiliki para calon pencari kerja agar kualifikasi yang dibutuhkan pihak pencari tenaga kerja dalam hal ini perusahaan dapat merekrut dengan mudah. Selain itu calon sarjana harus memiliki kemampuan dan kualitas yang baik sesuai dengan bidang pendidikan dan kompetensinya sehingga memudahkan dalam memilih orientasi bidang pekerjaan yang akan digeluti. 
Research and Development Journal Of Education

Vol. 5 No. 2 April 2019

p-ISSN 2406-9744

e-ISSN 2657-1056

\section{TINJAUAN PUSTAKA}

\section{Kualitas Lulusan Perguruan Tinggi}

Universitas atau Perguruan Tinggi adalah lembaga, institusi pendidikan yang melahirkan Sumber Daya Manusia (SDM) berupa lulusan yang diharapkan siap diserap oleh masyarakat dalam hal ini pemilik faktor produksi sebagai penggunanya. Alumni/lulusan merupakan ujung tombak akuntabilitas sebuah Perguruan Tinggi/lembaga di mata masyarakat. Keberadaan dan aktivitasnya akan membawa atribut kualitas lulusan, kelebihan, keunikan maupun kekurangan Perguruan Tinggi tersebut tidak akan lepas dari lulusan institusi itu sendiri.

Perguruan Tinggi pada dasarnya hadir dengan harapan sebagai lembaga pendidikan yang dapat membangun linkage antara satuan pendidikan di sekolah dan dunia kerja yang sebenarnya. Perguruan Tinggi sebagai jembatan untuk mempersiapkan lulusan pendidikan dari sekolah mulai dari sekolah dasar hingga menengah menjadi tenaga kerja yang siap pakai dan siap diberdayagunakan keahliannya. Lulusan perguruan tinggi ini dituntut untuk dapat memiliki value added bagi perusahaan yang akan mempekerjakannya secara optimal sehingga dapat memberikan feedback bagi kemajuan perusahaan tempat dia bekerja. Namun pada kenyataannya saat ini perguruan tinggi yang ada di Indonesia belum sama nilai dan kualitasnya dari berbagai segi keahlian. (M. Atma Adhyaksa \& Agus. R ; 2010)

Alumni/lulusan yang terserap pasar dengan optimal, baik mereka yang ingin berwirausaha maupun bekerja dengan orang lain. Hal ini akan menjadi dasar apakah keberadaan institusinya (program studi/jurusan/fakultas) masih akan dipertahankan atau tidak. Disisi lain ada faktor yang bisa meningkatkan kualitas perguruan tinggi dalam menghadapi persaingan dunia kerja antara lain visi dan misi, aturan, pedoman tata kelola lembaga, student body, sumber daya manusia, infrastruktur, tri dharma perguruan tinggi, kerjasama internasional, visiting lecture, dan isu yang berkembang saat ini.

Mengenai mutu pendidikan pada pasal 1 ayat 17 UU RI Nomor 20 Tahun 2003; bahwa : "Standar nasional pendidikan adalah kriteria minimal tentang sistem pendidikan di seluruh wilayah hukum Negara Kesatuan Republik Indinesia". Mengenai kriteria minimal standar nasional pendidikan ini terdiri atas standar isi, proses, kompetensi lulusan, tenaga kependidikan, sarana dan 
Research and Development Journal Of Education

Vol. 5 No. 2 April 2019

p-ISSN 2406-9744

e-ISSN 2657-1056

prasarana, pengelolaan, pembiayaan, dan penilaian pendidikan yang harus ditingkatkan secara berencana (Pasal 35 ayat 1 UU RI Nomor 20 Tahun 2003).

Untuk mencapai mutu yang standar dari pendidikan itu bukan hanya unsur tenaga kependidikan saja; yakni dosen tetapi bagaimana pengelolaan perguruan tinggi itu atas standar isi, proses, kompetensi lulusan, sarana dan prasarana, pengelolaan, pembiayaan, dan penilaian pendidikan; yang dapat dilaksanakan oleh suatu badan standardisasi, penjaminan dan pengendalian mutu pendidikan (Pasal 35 ayat 3 UU RI Nomor 20 Tahun 2003). Badan standarisasi, tersebut melakukan penjaminan dan pengendalian mutu pendidikan serta harus mampu dipersiapkan oleh pemerintah, dalam hal ini pengelolaan pendidikan tinggi di Indonesia, sehingga kualitas pendidikan dan lulusan perguruan tinggi memiliki kriteria minimal yang dibutuhkan dunia kerja harus senantiasa dipenuhi oleh pengelola pendidikan, yaitu baik pemerintah daerah maupun pemerintah pusat.

Untuk menggali informasi yang berkaitan dengan transisi dari dunia pendidikan ke dunia pekerjaan salah satu caranya dengan melaksanakan tracer study.Tracer study yaitu studi mengenai lulusan lembaga penyelenggara pendidikan tinggi. Istilah ini juga bisa digunakan sebagai "Graduate Surveys", "Responden Researches", dan "Follow-up Study". Tracer study ini menyediakan informasi untuk kepentingan evaluasi hasil pendidikan tinggi dan selanjutnya dapat digunakan untuk penyempurnaan serta penjaminan kualitas lembaga pendidikan tinggi bersangkutan. Tracer study ini juga memberikan dan menyediakan informasi yang sangat penting tentang hubungan antara pendidikan tinggi dengan dunia kerja maupun dunia usaha profesional, menilai relevansi pendidikan tinggi, dan informasi bagi pemangku kepentingan (stakeholders) dunia pendidikan, serta bagi kelengkapan persyaratan untuk melaksanakan akreditasi perguruan tinggi. Saat ini juga tracer study telah dijadikan salah satu persyaratan kelengkapan data bagi akreditasi di Indonesia oleh Badan Akreditasi Nasional Perguruan Tinggi (BAN-PT). (Schomburg, 2010)

Oleh karenanya, agar dapat meningkatkan sinergitas sistem dalam lembaga Perguruan Tinggi harus saling berhubungan, serta melakukan kegiatan bersama untuk memudahkan aliran informasi, materi atau energi di dalam Universitas yang bertujuan untuk memperoleh satu kesamaan informasi, keputusan bersama, pendapat, tujuan dan sasaran dalam membangun kehidupan 
Research and Development Journal Of Education

Vol. 5 No. 2 April 2019

p-ISSN 2406-9744

e-ISSN 2657-1056

kampus secara utuh dan menyeluruh. sehingga Diharapkan seluruh elemen dalam lembaga tersebut mempunyai kesamaam informasi, keputusan, pendapat, tujuan dan sasaran dalam menjalankan sistem kehidupan di universitas secara utuh. Robbins (dalam Udaya, 1994 428) menyatakan bahwa : Strategi cenderung masuk salah satu kategori dari empat kategori yang ada: manusia, struktur, teknologi, dan proses organisasi.

\section{Orientasi Bidang Pekerjaan}

Pada Perguruan Tinggi diperlukan adanya tujuan dan sasaran yang jelas dari orientasi bidang pekerjaan lulusan/alumni yang dihasilkan nantinya. Oleh karena itu Perguruan Tinggi hendaknya mampu memberikan sistem pendidikan yang sesuai dengan dunia kerja. Orientasi pada bidang pekerjaan dapat diartikan sebagai cara pandang atau harapan seseorang dalam keputusan untuk mengambil tindakan dalam jenis bidang pekerjaan yang akan digelutinya nanti. Oleh karena itu masing-masing individu akan saling berbeda orientasinya terhadap bidang pekerjaan tertentu termasuk mempengaruhi dalam keputusannya untuk memilih program jurusan/ fakultas di Perguruan Tingginya.

\section{Persaingan Kerja}

Persaingan di tempat kerja adalah sesuatu hal yang sangat wajar, karena di dalam perusahaan individu tidak melakukan segala sesuatunya sendirian. apabila persaingan kerja sudah berjalan tidak sehat akan menjadikan lingkungan kerja menjadi tidak nyaman bagi karyawan dan akan berdampak negative, sehingga bisa menghambat kreativitas karyawan untuk menghasilkan prestasi yang baik. Tujuan persaingan adalah untuk menuntut karyawan memunculkan kreativitas, keahlian dan aktualisasi potensi terpendam.

Hal ini pun dirasakan oleh para sarjana yang baru lulus kuliah, dimana persaingan kerja sudah bisa dirasakan oleh mereka, oleh karenanya persiapan kerja bagi alumni/lulusan sarjana harus benar-benar dipersiapkan. Menurut Brady (dalam Yosiana Nur Agusta 2015), kesiapan kerja adalah berfokus pada sifat-sifat pribadi, seperti sifat pekerja dan mekanisme pertahanan yang dibutuhkan, bukan hanya untuk mendapatkan pekerjaan, tetapi juga lebih dari itu yaitu untuk mempertahankan suatu pekerjaan.

Mempersiapkan diri dalam memasuki dunia kerja diperlukan suatu kesiapan yang matang dalam diri mahasiswa itu sendiri, terutama menyangkut ciri-ciri yang 
Research and Development Journal Of Education

Vol. 5 No. 2 April 2019

p-ISSN 2406-9744

e-ISSN 2657-1056

berhubungan dengan diri mahasiswa. Menurut Anoraga (dalam Yosiana Nur Agusta 2015) ciri-ciri kesiapan kerja sebagai berikut :

1. Memiliki motivasi

Makna motivasi dikatakan sebagai kebutuhan untuk mendorong perbuatan ke arah suatu tujuan tertentu. Jadi motivasi kerja adalah suatu yang menimbulkan semangat atau dorongan kerja. Kuat atau lemahnya motivasi kerja seorang tenaga kerja dapat menentukan besar kecilnya prestasinya.

2. Memiliki kesungguhan atau keseriusan

Kesungguhan atau keseriusan dalam bekerja memiliki andil dalam menentukan keberhasilan kerja. Sebab tanpa adanya itu semua suatu pekerjaan tidak akan dapat berjalan sesuai dengan yang diinginkan. Jadi untuk melakukan suatu pekerjaan dibutuhkan adanya kesungguhan dan keseriusan, supaya pekerjaan berjalan dengan baik dan selesai sesuai dengan target yang diinginkan.

3. Memiliki keterampilan yang cukup

Keterampilan memiliki makna kecakapan atau cekatan dalam mengerjakan sesuatu atau penguasaan individu terhadap suatu perbuatan atau aktivitas. Jadi untuk memasuki pekerjaan sangat dibutuhkan suatu keterampilan sesuai dengan pekerjaan yang dipilihnya, yaitu keterampilan dalam mengerjakan tugasnya serta mengambil keputusan sendiri (problem solving) tanpa pengaruh dari orang lain dengan alternatif-alternatif yang akan dipilih.

4. Memiliki kedisiplinan

Disiplin adalah suatu sikap, perbuatan untuk selalu mengikuti suatu tata tertib dengan baik. Jadi untuk memasuki suatu pekerjaan sikap disiplin sangat diperlukan demi peningkatan prestasi kerja. Seorang pekerja yang memiliki disiplin tinggi, masuk kerja tepat pada waktunya, demikian juga pulang pada waktunya dan selalu taat pada tata tertib.

\section{METODE}

Penelitian ini menggunakan metode Kuantitatif dengan melihat semua subjek yang sesuai dengan karakteristik pada populasinya. Penelitian yang meneliti semua elemen yang ada dalam wilayah penelitian, maka penelitian disebut penelitian populasi atau studi populasi, dalam penelitian ini populasi yang 
Research and Development Journal Of Education

Vol. 5 No. 2 April 2019

p-ISSN 2406-9744

e-ISSN 2657-1056

ada adalah mahasiswa yang mengikuti program pelatihan Sertifikasi Zahir Accounting Pada LPP Universitas Indraprasta PGRI sebanyak 218 mahasiswa, sehingga diambil sampel sebanyak 104 orang mahasiswa tingkat semester akhir. Penelitian ini menggunakan tiga variabel yaitu Skala Kualitas Lulusan Perguruan Tinggi, Orientasi Bidang Pekerjaan dan Kemampuan Menghadapi Persaingan Kerja. Dengan kisi-kisi indikator penelitian sebagai berikut:

1. Kualitas Lulusan Perguruan Tinggi

a. Memiliki akhlak dan pekerti

b. Indeks Prestasi Mahasiswa

c. Kompetensi penguasaan bidang ilmu tertentu

d. Memiliki kemampuan bekerjasama dan jaringan

2. Orientasi Bidang Pekerjaan

a. Posisi jenis pekerjaan pada perusahaan

b. Pengembangan karir pekerjaan

c. Panggilan hati pada jenis pekerjaan

d. Kebermanfaatan jenis pekerjaan

3. Kemampuan Menghadapi Persaingan Kerja

a. Memiliki semangat tinggi pada bidang pekerjaan

b. Mampu beradaptasi pada tantangan pekerjaan

c. Mampu menerima posisi perkerjaan dengan baik

d. Mampu menempatkan posisi diri pada jenis keahlian yang dimiliki

Cara skoring yang digunakan adalah dengan memberi skor untuk pernyataan favourable (sangat disukai) dengan kriteria, skor 5 jika menjawab SS (Sangat Sesuai), skor 4 jika menjawab S (Sesuai), skor 3 jika menjawab N (Netral) skor 2 jika menjawab TS (Tidak Sesuai), dan skor 1 jika menjawab STS (Sangat Tidak Sesuai). Skor tertinggi untuk item favourable terletak pada jawaban "Sangat Sesuai" sedang untuk item yang unfavourable skor tertinggi terletak pada jawaban "Sangat Tidak Sesuai".

\section{HASIL DAN PEMBAHASAN}

Untuk memasuki dunia kerja yang penuh tantangan, maka setiap calon pekerja harus membekali dirinya dengan kemampuan yang baik untuk bisa bersaing dan unggul dengan para calon lainnya, sehingga pelamar kerja dapat 
Research and Development Journal Of Education

Vol. 5 No. 2 April 2019

p-ISSN 2406-9744

e-ISSN 2657-1056

memikat para pemberi kerja. Menurut Brady (dalam Yosiana Nur Agusta; 2015), kesiapan kerja adalah berfokus pada sifat-sifat pribadi, seperti sifat pekerja dan mekanisme pertahanan yang dibutuhkan, bukan hanya untuk mendapatkan pekerjaan, tetapi juga lebih dari itu yaitu untuk mempertahankan suatu pekerjaan.

Mempersiapkan diri dalam memasuki dunia kerja diperlukan suatu kesiapan yang matang dalam diri mahasiswa itu sendiri, terutama menyangkut ciri-ciri yang berhubungan dengan diri mahasiswa. Dilain sisi kualitas dari lulusan Perguruan Tinggi itu sendiri sangat mempengaruhi mahasiswa dalam mendapatkan suatu jenis pekerjaan yang sesuai dengan orientasinya dalam bidang pekerjaan. Untuk itu sikap dan kemampuan dalam persaingan memperoleh pekerjaan diperlukan oleh setiap lulusan.

Dari pengujian yang telah dilakukan dengan program SPSS dan jumlah sampel sebanyak 104 mahasiswa didapatkan hasil Pengujian sebagai berikut:

\section{Uji Normalitas}

Uji normalitas bertujuan untuk mengetahui apakah data hasil pengumpulan berdistribusi normal atau tidak. Hal ini akan berpengaruh pada proses lanjutan analisis statistik, jika data berdistribusi normal, maka analisis dilanjutkan menggunakan statistik parametrik, sedangkan jika data tidak berdistribusi normal, maka analisis dilanjutkan menggunakan statistik non parametrik. Uji normalitas dapat dilakukan menggunakan analisis Kolmogorov Smirnov dalam SPSS. Distribusi data dikatakan normal jika nilai sig KS > 0,05.

Tabel 1. Hasil uji normalitas data penelitian

One-Sample Kolmogorov-Smirnov Test

\begin{tabular}{llrr}
\hline & & $\begin{array}{c}\text { Unstandardized } \\
\text { Residual }\end{array}$ & $\begin{array}{c}\text { Standardized } \\
\text { Residual }\end{array}$ \\
\hline $\mathrm{N}$ & & 104 & 104 \\
Normal Parameters & Mean & .0000000 & .0000000 \\
& Std. Deviation & 3.28843298 & .99790472 \\
Most Extreme Differences & Absolute & .220 & .220 \\
& Positive & .220 & .220 \\
& Negative & -.091 & -.091 \\
Kolmogorov-Smirnov Z & & .761 & .761 \\
Asymp. Sig. (2-tailed) & & .524 & .524 \\
\hline a. Test distribution is Normal. & & \\
b. Calculated from data. & & & \\
& & &
\end{tabular}


Research and Development Journal Of Education

Vol. 5 No. 2 April 2019

p-ISSN 2406-9744

e-ISSN 2657-1056

Pada tabel di atas terlihat bahwa nilai pada kolom Sig $=0,524>0,05$ pada metode Kolmogorov-Smirnov, dengan kata lain bahwa data dari semua sampel pada penelitian ini berdistribusi normal. Uji normalitas ini bertujuan untuk mengetahui apakah model regresi dalam variabel bebas dan variabel terikat harus berdistribusi normal.

\section{Uji Homogenitas}

Menurut ketentuan yang ada pada program tersebut maka kriteria dari homogenitas data adalah "jika $p$ value ( $\mathrm{sig})>0.05$ yang berarti bahwa sampelsampel tersebut berasal dari populasi yang homogen. Nilai $p$ value (sig) adalah bilangan yang tertera pada kolom sig dalam tabel hasil/output perhitungan pengujian homogenitas oleh program SPSS.

Tabel 2. Rekapitulasi Hasil Pengujian Homogenitas

\begin{tabular}{ccccc}
\multicolumn{5}{c}{ Test of Homogeneity of Variances } \\
\hline & Levene Statistic & df1 & df2 & Sig. \\
\hline Kualitas_Lulusan & 3.026 & 19 & 32 & .075 \\
Orientasi_Bidang_Pekerjaan & 2.421 & 19 & 32 & .083 \\
\hline
\end{tabular}

Pada tabel di atas terlihat bahwa nilai pada kolom Sig untuk semua sampel lebih besar dari 0,05, sehingga dapat dikatakan bahwa sampel-sampel tersebut berasal dari populasi yang homogen.

Berdasarkan hasil pengujian pada program SPSS didapat output secara parsial pengaruh dari variabel independen yaitu Kualitas Lulusan dan Orientasi Bidang Pekerjaan terhadap variabel dependen yaitu Kemampuan Menghadapi Persaingan Kerja, dapat disusun persamaan regresi linear berganda sebagai berikut: $\mathrm{Y}=9,189+0,348 \mathrm{X}_{1}+0,243 \mathrm{X}_{2}$

Tabel 3. Persamaan Garis Regresi berganda Pengaruh Variabel $X_{1}$ dan $X_{2}$ terhadap Variabel Y

Coefficients $^{\mathrm{a}}$

\begin{tabular}{|c|c|c|c|c|c|c|}
\hline & & \multicolumn{2}{|c|}{$\begin{array}{l}\text { Unstandardized } \\
\text { Coefficients }\end{array}$} & \multirow{2}{*}{$\begin{array}{c}\text { Standardized } \\
\text { Coefficients }\end{array}$} & \multirow[b]{2}{*}{$\mathrm{T}$} & \multirow[b]{2}{*}{ Sig. } \\
\hline \multicolumn{2}{|c|}{ Model } & $\mathrm{B}$ & Std. Error & & & \\
\hline \multirow[t]{3}{*}{1} & (Constant) & 9.189 & 5.131 & & 4.120 & .000 \\
\hline & Kualitas Lulusan & .348 & .059 & .458 & 4.184 & .000 \\
\hline & Orientasi Bidang Pekerjaan & .243 & .047 & .333 & 3.044 & .004 \\
\hline
\end{tabular}

a. Dependent Variable: Kemampuan Persaingan Kerja 
Research and Development Journal Of Education

Vol. 5 No. 2 April 2019

p-ISSN 2406-9744

e-ISSN 2657-1056

\section{Uji Goodness Of Fit}

Secara statistik uji ini digunakan untuk mengukur nilai statistik t, nilai statistik F, dan koefisien determinasi ( $\mathrm{R}$ square/ $\mathrm{R}^{2}$ ). Dari hasil perhitungan di dapat output dalam tabel dibawah ini:

Tabel 4. Koefisien Korelasi Pengaruh Variabel $\mathrm{X}_{1}$ dan $\mathrm{X}_{2}$ terhadap Variabel $\mathrm{Y}$

Model Summary

\begin{tabular}{|c|c|c|c|c|c|c|c|c|c|}
\hline \multirow[b]{2}{*}{ Model } & \multirow[b]{2}{*}{$\mathrm{R}$} & \multirow[b]{2}{*}{ R Square } & \multirow[b]{2}{*}{$\begin{array}{l}\text { Adjusted R } \\
\text { Square }\end{array}$} & \multirow[b]{2}{*}{$\begin{array}{l}\text { Std. Error of } \\
\text { the Estimate }\end{array}$} & \multicolumn{5}{|c|}{ Change Statistics } \\
\hline & & & & & $\begin{array}{l}\text { R Square } \\
\text { Change }\end{array}$ & F Change & df1 & df2 & $\begin{array}{c}\text { Sig. F } \\
\text { Change }\end{array}$ \\
\hline 1 & $.780^{\mathrm{a}}$ & .608 & .583 & 6.392 & .562 & 11.453 & 2 & 102 & .000 \\
\hline
\end{tabular}

a. Predictors: (Constant), Kualitas Lulusan, Orientasi Bidang Pekerjaan

b. Dependent Variable: Kemampuan Persaingan Kerja

Dari tabel diatas terlihat bahwa koefisien korelasi berganda pengaruh variabel $X_{1}$ dan $X_{2}$ secara bersama-sama terhadap variabel $Y$ adalah sebesar 0,780. Maka berdasarkan nilai $\mathrm{r}$ hitung korelasi tersebut memiliki hubungan keberpengaruhan dalam kategori Kuat. Dimana pengaruh variable $\mathrm{X}_{1}$ (Kualitas Lulusan) dan Variabel $\mathrm{X}_{2}$ (Orientasi Bidang Pekerjaan) dalam penelitian ini berpengaruh kuat terhadap variable Y (Kemampuan Persaingan Kerja). Kemudian nilai $\mathrm{R}^{2}$ diperoleh $0,608(60,8 \%)$ hal ini menunjukkan kemampuan persaingan kerja dipengaruhi oleh kualitas lulusan dan orientasi bidang pekerjaan sebesar $60,8 \%$ sedangkan sisanya sebesar 39,2\% dipengaruhi oleh faktor lain yang tidak dijelaskan pada penelitian ini.

\section{Uji F}

Uji $\mathrm{F}$ ini digunakan untuk mengetahui pengaruh bersama variabel independen terhadap variabel dependen. Dari hasil pengujian di dapat pengujian signifikasi garis regresi tersebut terlihat bahwa nilai $p$ value $($ sig $)=0.000<0.005$, dan $\mathbf{F}_{\text {hitung }} \mathbf{1 4 , 2 4 3}$. Dengan kata lain bahwa terdapat pengaruh yang signifikan variabel bebas $\mathrm{X}_{1}$ (Kualitas Lulusan) dan $\mathrm{X}_{2}$ (Orientasi Bidang Pekerjaan) secara bersama-sama terhadap variabel terikat Y (Kemampuan Persaingan Kerja).

Tabel 5. Pengujian Signifikasi Koefisien Regresi Pengaruh Variabel $X_{1}$ dan $X_{2}$ terhadap Variabel Y 
Research and Development Journal Of Education

Vol. 5 No. 2 April 2019

p-ISSN 2406-9744

e-ISSN 2657-1056

\begin{tabular}{llrrrrr}
\multicolumn{7}{c}{ ANOVA $^{\mathbf{b}}$} \\
\hline Model & & Sum of Squares & Df & Mean Square & F & \multicolumn{1}{c}{ Sig. } \\
\hline 1 & Regression & 1325.645 & 2 & 720.822 & 14.243 & $.000^{\mathbf{a}}$ \\
& Residual & 2436.955 & 101 & 19.078 & & \\
& Total & 2738.600 & 102 & & & \\
\hline
\end{tabular}

a. Predictors: (Constant), Kualitas Lulusan, Orientasi Bidang Pekerjaan

b. Dependent Variable: Kemampuan Persaingan Kerja

\section{Uji t}

Uji t bertujuan untuk mengetahui pengaruh variabel independen terhadap variabel dependen secara individual. Dari hasil analisis regresi berganda diatas didapatkan nilai sig (signifikan) variabel Kualitas Lulusan (X1) terhadap Kemampuan Persaingan kerja yaitu sebesar $0,000(0,000<0.05)$ ini berarti terdapat pengaruh Kualitas Lulusan terhadap Kemampuan Persaingan Kerja. Sedangkan pada nilai sig (signifikan) variabel Orientasi Bidang Pekerjaan (X2) sebesar $0.004(0,004<0,05)$ ini berarti terdapat pengaruh Orientasi Bidang Pekerjaan terhadap Kemampuan Persaingan Kerja.

\section{SIMPULAN}

Berdasarkan hasil analisis dalam penelitian ini dan hasil deskripsi data penelitian maka dapat disimpulkan :

1. Terdapat pengaruh yang signifikan Kualitas Lulusan dan Orientasi Bidang Pekerjaan secara bersama-sama terhadap Kemampuan Menghadapi Persaingan Kerja. Hal ini dibuktikan oleh $\quad F_{\text {hitung }}=14,243$ dan sig. $0,000<$ 0,05 dan koefisien determinasi $\mathrm{R}^{2}$ sebesar 0,608 (60,8\%)hal ini menunjukkan kemampuan persaingan kerja dipengaruhi oleh kualitas lulusan dan orientasi bidang pekerjaan sebesar $60,8 \%$ sedangkan sisanya sebesar 39,2\% dipengaruhi oleh faktor lain yang tidak dijelaskan pada penelitian ini, dan persamaan garis regresi $Y=9,189+0,348 X_{1}+0,243 X_{2}$.

2. Terdapat pengaruh yang signifikan Kualitas Lulusan terhadap Kemampuan Menghadapi Persaingan Kerja.Hal ini dibuktikan oleh Sig. $0.00<0.05$.

3. Terdapat pengaruh yang signifikan Orientasi Bidang Pekerjaan terhadap Kemampuan Menghadapi Persaingan Kerja.Hal ini dibuktikan oleh Sig. 0.004 $<0.05$ 
Research and Development Journal Of Education

Vol. 5 No. 2 April 2019

p-ISSN 2406-9744

e-ISSN 2657-1056

\section{DAFTAR PUSTAKA}

Agung, I Gusti Ngurah. (2004). Statistika Penerapan Model Analisis untuk Tabulasi Sempurna dan Tidak Sempurna dengan SPSS. Jakarta: Raja Grafindo Persada

Damayanti, M. Ria, A. \& Zainuddin, D. (2018). Pengaruh Pelatihan Sertifikasi Zahir Accounting terhadap Kesiapan Kerja Mahasiswa Program Studi Pendidikan Ekonomi. Jurnal Prosiding LPPM Unindra 2018

Ibrahim, A. Suparman. (2014). Aplikasi Komputer Dalam Menyusun Karya Ilmiah. Tangerang: Pustaka Mandiri

Kusdyah, Ike Rachmawati. (2008). Manajemen Sumber Daya Manusia. Yogyakarta: Penerbit Andi

M. Atma Adhyaksa \& Agus. R. (2010). Persepsi Dunia Kerja Terhadap Lulusan Fresh Graduate S1 Menggunakan Multidimensional Unfolding (Studi Kasus: Dunia Usaha di Kabupaten Batang). Jurnal Media Statistika, Vo. 3 No.1, 49-57

Robbins, Stephen P. Terj. Yusuf Udaya. (2004). Teori Organisasi, Struktur, Desain dan Aplikasi. Jakarta : Arcan.

Syahrina, I, A, \& Sari Wulan, M. (2015). Orientasi Masa Depan Bidang Pekerjaan dengan Motivasi Berprestasi Remaja Atlet Sepak Bola. Jurnal RAP UNP, 6 (2), 157-168

Sugiyono. (2018). Metode Penelitian Kombinasi (Mix Methods). Bandung: Alfabeta

Undang-Undang Republik Indonesia Nomor 20 Tahun 2003 Tentang Sistem Pendidikan Nasional

Yosiana Nur Agusta.(2015). Hubungan Antara Orientasi Masa Depan dan Daya Juang Terhadap Kesiapan Kerja Pada Mahasiswa Tingkat Akhir Fakultas Ilmu Sosial dan Ilmu Politik di Universitas Mulawarman (ejurnal.psikolog.fisip-umnul.org), diakses pada 20 Februari 2019.

Schomburg, dlm. http://alumni.ui.ac.id/content/hasil-tracer-study-2010. Diakses 20 Februari 2019

Https://beritagar.id/artikel/berita/masih-ada-7-juta-pengangguran-di-indonesia. diakses pada 08 Mei 2019 